\title{
A newborn with ring chromosome 10, aganglionic megacolon, and renal hypoplasia
}

Giuseppe Calabrese, Paolo Guanciali Franchi, Liborio Stuppia, Rita Mingarelli, Carlo Rossi, Luca Ramenghi, Mario Marino, Elisena Morizio, Rita Peila, Adriano Antonucci, Giandomenico Palka

\begin{abstract}
A newborn infant is reported who had aganglionic megacolon, renal hypoplasia, severe growth retardation, generalised hypotonia, and various dysmorphic features. Chromosome analysis of lymphocytes and fibroblasts showed a ring chromosome 10 with breakpoints at p1315 and q26. AluI digestion showed that the ring chromosome was monocentric. FISH with an $\alpha$ satellite probe specific for chromosome 10 showed one signal only in about $20 \%$ of interphase nuclei. It is suggested that aganglionic megacolon could result from dynamic somatic mosaicism owing to loss of the ring chromosome.
\end{abstract}

( $(\mathcal{H}$ Med Genet 1994;31:804-806)

Rings have been identified for all human chromosomes and are usually associated with growth and mental retardation when autosomes are involved.

Ring formation results from deletion of the Genetica, Università di Chieti, Italy G Calabrese P G Franchi M Marino E Morizio G Palka

Istituto di Morfologia Umana, Università di Chieti, Italy

A Antonucci

Istituto di Chirurgia Pediatrica, Università di Chieti, Italy

C Rossi

Istituto di Patologia Neonatale, Universita di Chieti, Italy

L Ramenghi

Istituto di

Citomorfologia Normale e Patologica CNR, Chieti, Italy

L Stuppia

$R$ Peila

Servizio di Genetica Medica, IRCCS Casa Sollievo della

Sofferenza, S Giovanni Rotondo (FG), Italy R Mingarelli

Correspondence to Dr Palka, Via B Buuzzi 93 65121 Pescara, Italy.

Received 7 January 1994 Received 7 January 1994 publication 17 May 1994 distal chromosomal ends. However, evidence provided by molecular techniques has shown that telomeric sequences may be maintained at the breakpoint junction. ${ }^{1}$ Telomeres play a crucial role in preserving the structure of chromosome ends and their absence results in chromosome instability which may cause a more severe phenotype. ${ }^{1-3}$ Only a few patients with ring chromosome 10 have been reported. The first patient was described by Lansky et $a l^{4}$ and other observations have since been reported. ${ }^{5-12}$ Severe growth and mental retardation and a pattern of congenital malformations and dysmorphism are invariably found in the $r(10)$ patients. Moreover, ring chromosome instability, leading to dynamic somatic mosaicism, may also be implicated in tumorigenesis or abnormal fetal development when tumour suppressor genes or genes involved in embryogenesis are lost. ${ }^{9-11}$

We report an additional newborn patient with a $r(10)$ chromosome presenting with aganglionic megacolon, renal hypoplasia, and a pattern of dysmorphism.

\section{Case report}

The proband, a female, was the first child of unrelated parents. The family history was unremarkable. At birth the mother was 28 years old and the father 31 . The baby was delivered by caesarian section after 38 weeks of gestation. The pregnancy was complicated by threatened abortion in the third month, which was treated with gonadotrophin. Birth weight was $1750 \mathrm{~g}$, length $41 \mathrm{~cm}$, and head circumference $29 \mathrm{~cm}$ ( $<3$ rd centile). Apgar was 9 at five minutes. Physical examination showed frontal bossing, hypertelorism, microphthalmia, downward slanting palpebral fissures, mildly stubby nose, large nares, long philtrum, thin lips, micrognathia, low set ears with thin helices, prominent antihelices and large lobules, short neck, increased internipple distance, mild pectus excavatum, long tapering fingers, and a gap between the hallux and the second toe. There was severe hypotonia with reduced muscle mass (fig 1). At 1 month, a megacolon of the sigmoid, resulting from rectal aganglionosis confined to the segment below the splenic flexure, was diagnosed and surgically corrected. At that time the baby weighed $1700 \mathrm{~g}$.

Hypocalcaemia was detected on different occasions $(6.5 \mathrm{mg} / \mathrm{ml})$, while parathormone was normal (39 pmol/1). Hypogammaglobulinaemia and depletion of $\mathrm{T}$ lymphocytes $(20 \%$ of normal) were also present. A pelvic ultrasound analysis and scintigraphy showed renal hypoplasia.

At 40 days, the baby developed convulsions which were resistant to conventional therapy. At this time, progressive renal failure was noticed which was the cause of death in the third month.

\section{Materials and methods}

CYTOGENETIC ANALYSIS

Chromosome analysis was carried out using a high resolution technique ${ }^{12}$ and GTG and AluI banding on both peripheral lymphocytes and fibroblasts obtained from a skin biopsy of the patient. Cytogenetic analysis was also carried out on peripheral lymphocytes of the parents.

\section{FLUORESCENCE IN SITU HYBRIDISATION}

FISH analysis was performed according to Pinkel $e t a l^{13}$ using a cocktail probe for the telomere regions (ONP5097, Oncor Inc, USA). Two colour FISH analysis was carried out using two $\alpha$ satellites specific for chromosomes 10 and $X$ (ONP5020 and ONP5060, Oncor Inc, USA) and FISH images were recorded using an Axioskop microscope (Zeiss, Germany) equipped with a CCD camera (Photometrics, USA) operated by a Zeiss Vidas image analyser. 

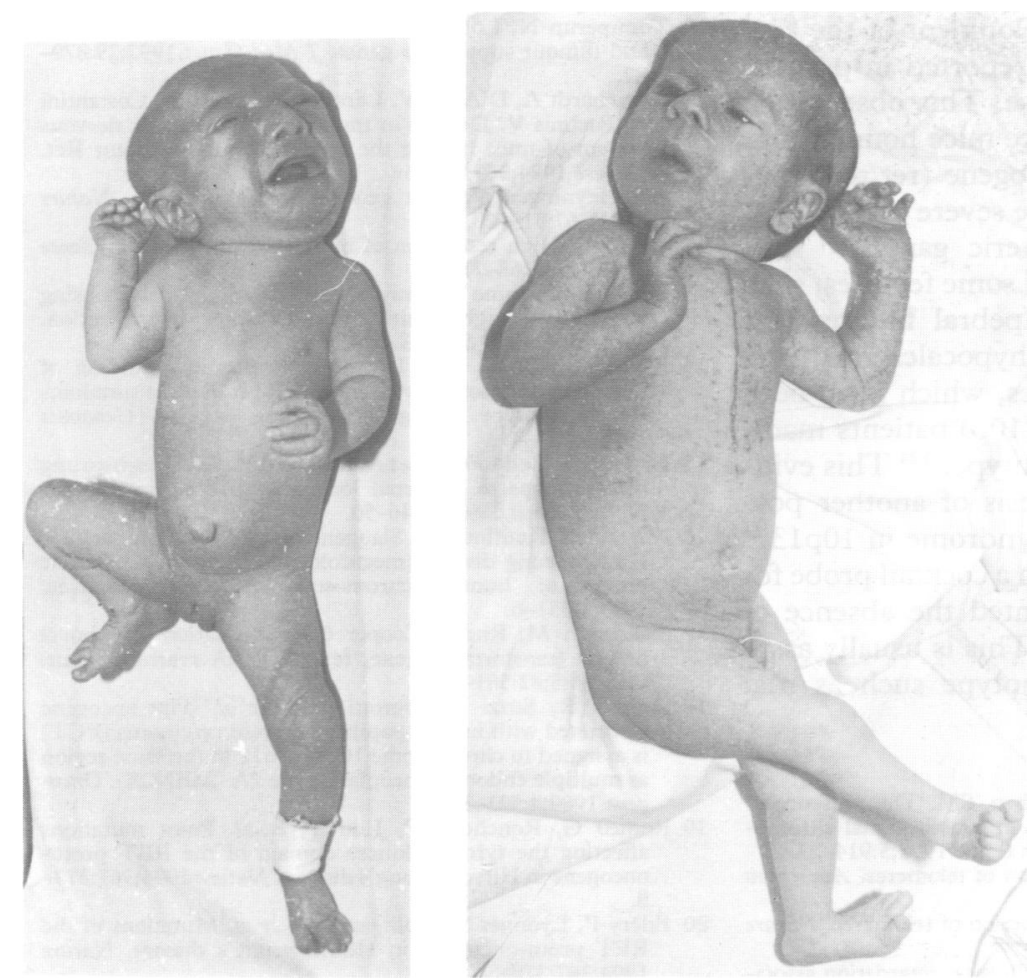

Figure 1 The proband at 15 days (left) and 40 days (right).
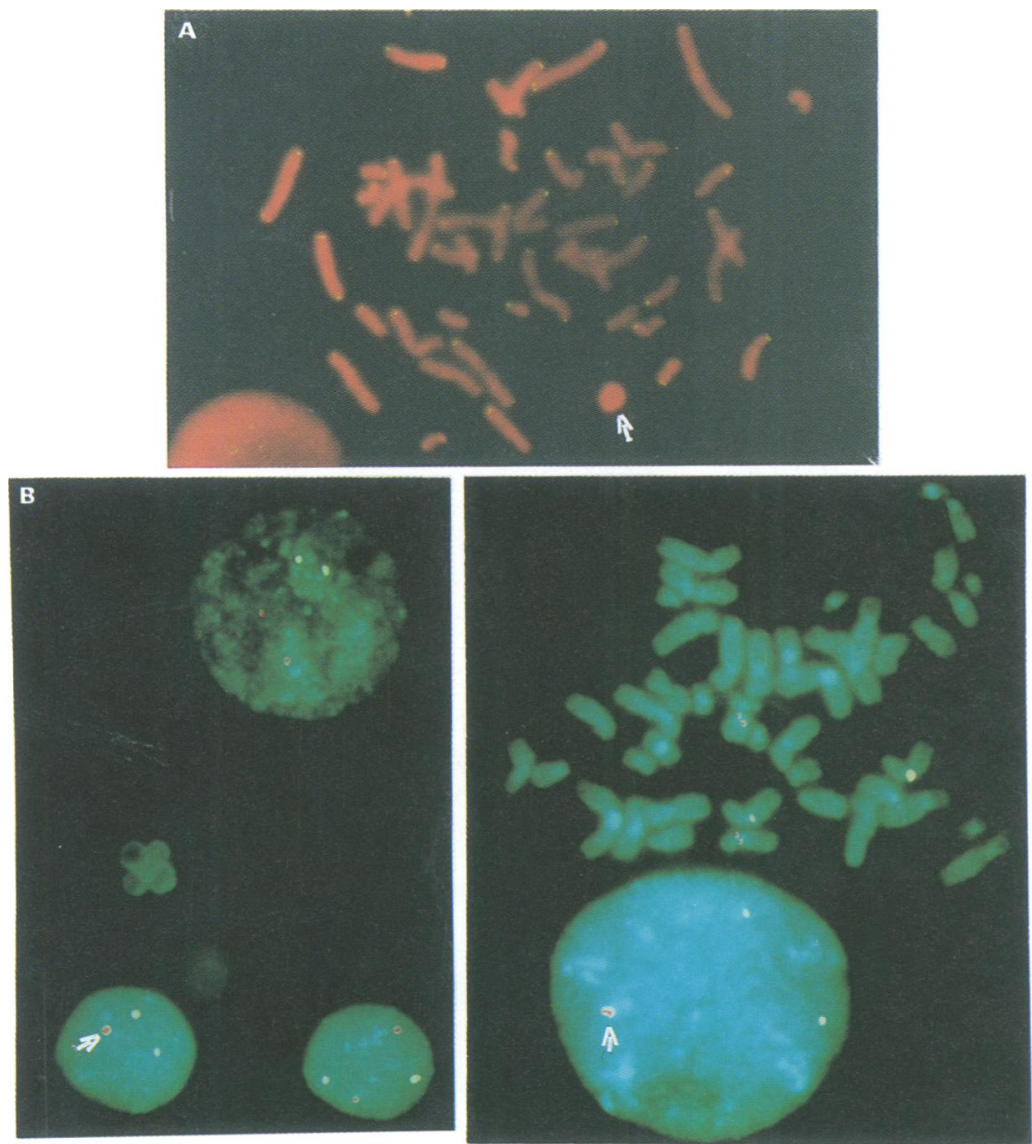

Figure 3 (A) FISH with probe ONP5097 specific for telomeric regions showing the absence of telomeric sequences in the ring chromosome 10 (arrow). (B) Two colour FISH with $\alpha$ satellite DNA specific for chromosome 10 (red signals) and X chromosome (yellow signals) showing, in two interphase nuclei of peripheral blood lymphocytes, only one signal for chromosome 10 (arrows).

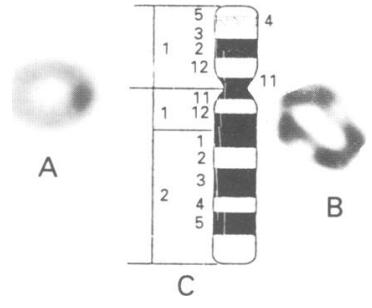

Figure 2 Two different $r(10)$ chromosomes from selected cells showing AluI banding $(A)$ and GTG banding $(B$ ) compared with an idiogram of $G$ banded chromosome 10 (C).

Fluorescein (Vector, USA) and Rhodamine (Boehringer, Germany) signals as well as diaminophenilindole (DAPI, Sigma, USA) counterstained nuclei and metaphases were recorded as separate grey scale images, pseudocoloured, and then electronically merged. ${ }^{14}$

\section{Results}

Four of 100 metaphases (50 from lymphocytes and 50 from fibroblasts) showed a modal number of 45 chromosomes, with monosomy of chromosome 10. In the other euploid cells one chromosome 10 was replaced by a ring structure, with breakpoints at 10p13-15 and 10q26 (fig 2A). AluI banding showed that the ring was monocentric (fig 2B). No telomeric sequence was detected on the $r(10)$ with a probe specific for telomeres (fig 3A). Two colour experiments with $\alpha$ satellite probes showed four signals in 199 of 250 consecutive lymphocyte interphase nuclei and in 87 of 100 fibroblast nuclei. Two signals were detected by the $\alpha$ satellite probe for chromosome 10 and two by the $\mathrm{X}$ chromosome probe. In the other cells, only one signal specific for chromosome 10 was detected. This finding was in agreement with monosomy 10 in a proportion of nuclei examined (fig 3B).

\section{Discussion}

The present patient had aganglionosis of the colon which, to the best of our knowledge, has never been found before in association with $r(10)$. Recently, a locus for Hirschsprung's disease has been assigned to band 10q11.2, where the proto-oncogene RET has been mapped. ${ }^{15-18}$ RET gene mutations have been associated with multiple endocrine neoplasia as well as with Hirschsprung's disease. ${ }^{19-22}$ In aganglionosis of the colon, RET mutations lead to inactivation or abrogation of functional gene product. ${ }^{1122} \mathrm{It}$ appears that $50 \%$ loss of RET gene product in affected cells is enough to result in Hirschsprung's disease. ${ }^{1122}$ In the present case cytogenetic and FISH analyses performed on lymphocytes and fibroblasts showed monosomy 10 in about $4 \%$ of metaphases and $20 \%$ of interphase nuclei. Although this discrepancy may be the result of the proliferative advantage of cultured cells with a ring chromosome, the evidence of somatic loss of the $r(10)$ chromosome corroborates the hypothesis that gene loss owing to the dynamic somatic mosaicism of the $\mathbf{r}(10)$ in enteric ganglia might explain the occurrence of Hirschsprung's disease. Moreover, this 
patient had abnormal development of the kidneys, which has not been reported in patients with Hirschsprung's disease. This observation is of particular interest since mice homozygous for the mutated RET oncogene (ret/ret) have recently been found to have severe kidney dysplasia and absence of enteric ganglia. ${ }^{10}$ The present patient also showed some features, such as downward slanting palpebral fissures, ear anomalies, micrognathia, hypocalcaemia, and depletion of $\mathrm{T}$ lymphocytes, which have been reported previously in del(10p) patients manifesting the DiGeorge phenotype. ${ }^{2324}$ This evidence supports the hypothesis of another possible locus for DiGeorge syndrome in $10 \mathrm{p} 13 .^{24}$ Finally, FISH analysis with a cocktail probe for telomeric regions documented the absence of telomeres within the ring. This is usually associated with a severe phenotype such as that observed in our patient. ${ }^{12}$

1 Park VM, Gustashaw KM, Wathen TM. The presence of interstitial telomeric sequences in constitutional chromo-
some abnormalities. Am $\mathcal{F}$ Hum Genet 1992;5:914-23.

2 Zakian VA. Structure and function of telomeres. Annu Rev Genet 1989;2:579-4.

3 Blackburn EH. Structure and function of telomeres. Nature 1991;3:569-73.

4 Lansky S, Daniel W, Fleizar K. Physical retardation associated with ring chromosome mosaicism: 46,XX,r(10)/ 45,XX,10-. F Med Genet 1977;14:61-3.

5 Fryns P, De Boeck K, Jaken J, van den Berg H. Malformative syndrome associated with a ring 10 chromosome and translocated $10 \mathrm{q} / 19$ chromosome. Hum Genet 1978; 43:239-44.

6 Sparkes RS, Ling SM, Muller H. Ring 10 chromosome: 46,XX,r(10)(p15q26). Hum Genet 1978;43:341-5.

7 Simoni G, Rossella F, Dalpra L, Visconi G, Piria-Schwaz C. Ring chromosome 10 associated with multiple congenital malformations. Hum Genet 1979;51:117-21.

8 Tsukino R, Tsuda N, Dezawa T, Ishii T, Koike M. Ring chromosome 10: 46,XX,r(10)(p15-q26). f Med Genet 1980;17:148-50.
9 Tommerup N, Lothe R. Constitutional ring chromosomes and tumour suppressor genes. 7 Med Genet 1992;29:879 82.

10 Schuchardt A, D'Agati V, Larsson-Blombery L, Costantini $F$, Pachnis V. Defects in the kidney and enteric nervous system of mice lacking the tyrosine kinase receptor Ret. Nature 1994;367:380-3.

11 van Heyningen V. One gene - four syndromes. Nature 1994;367:319-20

12 Yunis JJ. High resolution of human chromosomes. Science 1976;191:1268-71.

13 Pinkel D, Straume T, Gray VW. Cytogenetic analysis using quantatitive high-sensitivity fluorescence hybridization quantatitive high-sensitivity fluorescence
Proc Natl Acad Sci USA 1986;83:2934-8.

14 Baldini A, Ward DC. In situ hybridization banding of human chromosomes with Alu-PCR products: a simultanhuman chromosomes with Alu-PCR products: a simultaneous karyotyp
1991;9:770-4.

15 Lyonnet S, Bolino A, Pelet A, et al. A gene for Hirschsprung disease maps to proximal long arm of chromosome 10 Nature Genet 1993;4:346-50.

16 Angrist M, Kauffman E, Slaugenhaupt SA, et al. A gene for Hirschsprung disease (megacolon) in the pericentromeric region of human chromosome 10. Nature Genet 1993;4:351-6.

17 Takahashi M, Rita J, Cooper GM. Activation of a novel human transforming gene, ret, by DNA rearrangement. Cell 1985;42:581-8.

18 Donghi R, Sozzi G, Pierotti MA, et al. The oncogene associated with human papillary thyroid carcinoma (PCT) is assigned to chromosome $10 \mathrm{q} 11 \rightarrow \mathrm{q} 12$ in the same region as multiple endocrine neoplasia type $2 \mathrm{~A}$ (MEN2A). Oncogene 1989;4:521-3.

19 Romeo G, Ronchetto P, Luo Y, et al. Point mutations affecting the tyrosine kinase domain of the RET protoaffecting the tyrosine kinase domain of the RET proto-
oncogene in Hirschsprung's disease. Nature 1994:367:3778.

20 Edery P, Lyonnet S, Mulligan LM, er al. Mutations of the RET proto-oncogene in Hirschsprung's disease. Nature 1994;367:378-80.

21 Hofstra RMW, Landsvater RM, Ceccherini I, et al. A mutation in the RET proto-oncogene, associated with multiple endocrine neoplasia type $2 \mathrm{~B}$ and sporadic medullary thyroid carcinoma. Nature 1994;367:375-6.

22 Luo I, Ceccherini I, Pasini B, et al. Close linkage with the RET proto-oncogene and boundaries of deletion mutations in autosomal dominant Hirschsprung disease. Hum Mol Genet 1993;2:1803-8.

23 Obregon MG, Mingarelli R, Giannotti A, Di Comite A, Spedicato FS, Dallapiccola B. Partial deletion 10p syndrome. Ann Genet (Paris) 1992;35:101-4.

24 Greenberg F. Di George syndrome: an historical review of clinical and cytogenetic features. $f$ Med Genet 1993;30:803-6. 